\title{
Low birth weight in Iran: Implications from a systematic review of the literature and meta-analysis in the period 1999-2017
}

\author{
Faezeh Ebadi ${ }^{1}$, Ahmad Ghashghaee ${ }^{1}$, Nicola Luigi Bragazzi ${ }^{2}$, Mariano Martini $^{3}$, Razieh Sepehrian ${ }^{4}$, Mozhgan sadat
} Ghaemmohamadi $^{1}$, Sahar Sadat Saeedi Shahri ${ }^{1}$, Meysam Behzadifar ${ }^{5}$, Aidin Aryankhesal ${ }^{4}$, Masoud Behzadifar*6

Received: 31 May 2017

Published: 13 Feb 2018

\section{Abstract}

Background: Low birth weight (LBW), a crucial determinant of neonatal complications, represents a major public health concern worldwide. Epidemiological research is of crucial importance for designing and implementing ad hoc interventions for this issue, helping and guiding decision- and policy-makers in each country to prevent the increased prevalence of LBW in infants through estimating the prevalence rate, identifying and controlling major risk factors. The present investigation aimed to systematically assess LBW prevalence rate in Iran and its determinants.

Methods: PubMed/Medline via Ovid, Embase, Web of Science and Scopus as well as Magiran, SID and Irandoc were searched from inception until November 2016. Also, the grey literature (via Google Scholar) was mined. The DerSimonian-Laird model was exploited. The I2 and Q-test tests were used to investigate heterogeneity between the studies. Sensitivity and subgroup analyses were performed to ensure the robustness and validity of our findings. Different cumulative meta-analyses were conducted stratifying according to the year of publication and sample size. Any potential bias in publication was assessed carrying out the Egger's test.

Results: LBW prevalence rate was estimated to be $8 \%$ (95\% CI: 7-9) in Iran. Sensitivity analysis confirmed the stability of finding. Studies were cumulated by the year of publication, and the results did not change pre- and post-cumulative meta-analysis. No publication bias could be observed.

Conclusion: LBW prevalence rate in Iran is well comparable with the prevalence figures of both developed and developing countries. This could be due to the health reforms implemented in Iran throughout the years.

Keywords: Low birth weight, Systematic review and meta-analysis, Iran

Copyright@ Iran University of Medical Sciences

Cite this article as: Ebadi F, Ghashghaee A, Luigi Bragazzi N, Martini M, Sepehrian R, Ghaemmohamadi M, Saeedi Shahri SS, Behzadifar M, Aryankhesal A, Behzadifar M. Low birth weight in Iran: implications from a systematic review of the literature and meta-analysis in the period $1999-2017$. Med J Islam Repub Iran. 2018(13 Feb);32:13. https://doi.org/10.14196/mjiri.32.13

\section{Introduction}

Low birth weight (LBW), a major determinant of neonatal complications, is a crucial public health concern worldwide (1). About 18 million infants are affected by LBW annually (2). The World Health Organization (WHO) defines LBW when the weight of the newborn is less than $2.5 \mathrm{~kg}(3)$.

Corresponding author: Dr Masoud Behzadifar, masoudbehzadifar@gmail.com

1. Student Research Committee, Department of Health Services Management, School of Health Management and Information Sciences, Iran University of Medical Sciences, Tehran, Iran.

2. School of Public Health, Department of Health Sciences (DISSAL), University of Genoa, Genoa, Italy.

3. Section of History of Medicine and Ethics, Department of Health Sciences (DISSAL), University of Genoa, Genoa, Italy.

4. Department of Health Services Management, School of Health Management and Information Sciences, Iran University of Medical Sciences, Tehran, Iran.

5. Department of Epidemiology, Faculty of Health and Nutrition, Lorestan University of Medical Sciences, Khorramabad, Iran.

6. Health Management and Economics Research Center, Iran University of Medical Sciences, Tehran, Iran.
Further, LBW is among the important factors affecting long-term mental and physical development in children and represents a major determinant of infant mortality (4). LBW can be caused by maternal disorders, including endocrinological impairments, like metabolic syndrome and diabetes, malignancies, arthritis, chronic heart diseases,

$\uparrow$ What is "already known" in this topic:

Low birth weight (LBW) is a major determinant of neonatal complications as well as of mental and physical development in children. About 18 million infants are affected by LBW annually.

\section{$\rightarrow$ What this article adds:}

This study aimed at determining LBW prevalence rate in Iran by performing a systematic review and meta-analysis. LBW prevalence rate was estimated to be $8 \%(95 \% \mathrm{CI}$ : 7-9], well comparable with the prevalence figures of both developed and developing countries. This could be due to the health reforms implemented in Iran throughout the years. 
stroke, hypertension, and dementia (5), among others. Poor diet, age, educatio n level, lack of proper prenatal care, gravidity and parity, as well as economic and social status of pregnant women are among the foremost factors predicting a higher risk of $\operatorname{LBW}(6,7)$.

Numerous researches have been carried out worldwide in order to assess the LBW prevalence rate, which has been computed to be $5-7 \%$ and $19 \%$ in economically developed and developing countries, respectively (8). Thus, significant differences can be observed in the prevalence rate of low LBW between these countries. Areas across the world with low socio-economic status and poor diet seem to have higher prevalence rate of LBW and, as a result, greater complications when compared to developed countries (9).

Epidemiological and clinical research is of crucial importance for designing and implementing ad hoc interventions for this issue, helping and guiding decision- and policy-makers in each country to prevent increased prevalence of LBW in infants through estimating the prevalence rate, identifying and controlling major risk factors. These mainly concern the social and economic status of the households (10).

In recent years, different researches have been performed to investigate LBW prevalence rate in various provinces in Iran. It is of utmost importance to examine LBW trend so that risk factors associated with it could be identified and possible ways to intervene to reduce it could be suggested. In addition, LBW is a crucial predictor of neonatal survival and development. For these reasons, we aimed at investigating LBW prevalence rate in Iran and its predictors and determinants.

\section{Methods \\ Search methods}

The results of the current investigation were reported according to the PRISMA items (11). Different databases/bibliographical thesauri (namely, PubMed/Medline via Ovid, Scopus, Embase, and Web of Science, as well as Magiran, SID and Irandoc) were searched from inception until April 2017. Also, the grey literature (via Google Scholar) was mined.

The search strategy included a proper string of keywords connected by adequate Boolean connectors, such as ("prevalence" OR "epidemiology" OR "frequency") AND ("low birth weight" OR "LBW") AND "Iran". Wildcard option and medical subject headings (MeSH) terms where used when appropriate. Moreover, reference lists of national and international articles written in Persian and English and conferences related to the topic were examined.

\section{Study selection}

Inclusion criteria were: i) observational studies, and ii) studies reporting the prevalence rate of LBW in Iran. Exclusion criteria were: i) case-reports, case-series, letters to the editor, editorials, commentaries and review studies and ii) studies with poor quality data.

\section{Data collection}

Two authors independently extracted the data including first author, publication year, sample size, number of LBW cases (based on gender), maternal age, geographic area of study, type of study and prevalence rate reported. Any controversy was resolved by discussion or through consultation of a third person as a judge.

\section{Quality assessment of studies}

Methodology quality of the studies included in the current review was evaluated using the STROBE items (12). Based on the scores obtained from the checklist, the studies were scored between 1-8 (low quality), 9-16 (medium quality) and 16-24 (good quality). Any disagreement among the two reviewers of the studies was resolved with discussion until consensus was reached.

\section{Statistical analysis}

In this study, the DerSimonian-Laird (13) random model was exploited to determine the LBW prevalence rate. Results were reported with a confidence interval of $95 \%$ $(95 \% \mathrm{CI})$. The $\mathrm{I}^{2}$ and Q-test tests were used to investigate heterogeneity between the studies (14). In addition, in order to examine the source of heterogeneity, metaregression analyses were carried out based on the publication year and sample size of included studies (15). Sensitivity and subgroup analyses were performed in order to ensure the robustness and validity of our findings (16). In particular, the subgroup analysis was performed based on the sample size, research geographic location, publication year, gender, study type, and study quality. Different cumulative meta-analyses were conducted based on the year of publication and sample size (17). Any potential bias in publication was assessed using the Egger's test (18).

Data were analyzed using the open source $\mathrm{R}$ software (version 3.4.0). In this study, $\mathrm{p}<0.05$ was considered as statistically significant.

\section{Results}

A total of 44 studies was finally selected for the present meta-analysis (19-62), as shown in the flow-chart in Fig. 1.

The main features of the selected researches are shown in Table 1. The total number of recruited participants was 178,209 .

\section{The overall prevalence of $L B W$}

The overall prevalence rate of LBW was computed to be $8 \%(95 \%$ CI $7-9)$ in Iran. For further details, the reader is referred to Fig. 2.

The main findings of the subgroup analysis are reported in Table 2. Publication year, geographical location, quality of included studies and sample size resulted statistically significant $(\mathrm{p}=0.01)$.

\section{Predictors and determinants of LBW in Iran}

Table 3 highlights the main determinants and predictors/variables of LBW, on the basis of the findings of the present meta-analysis. 

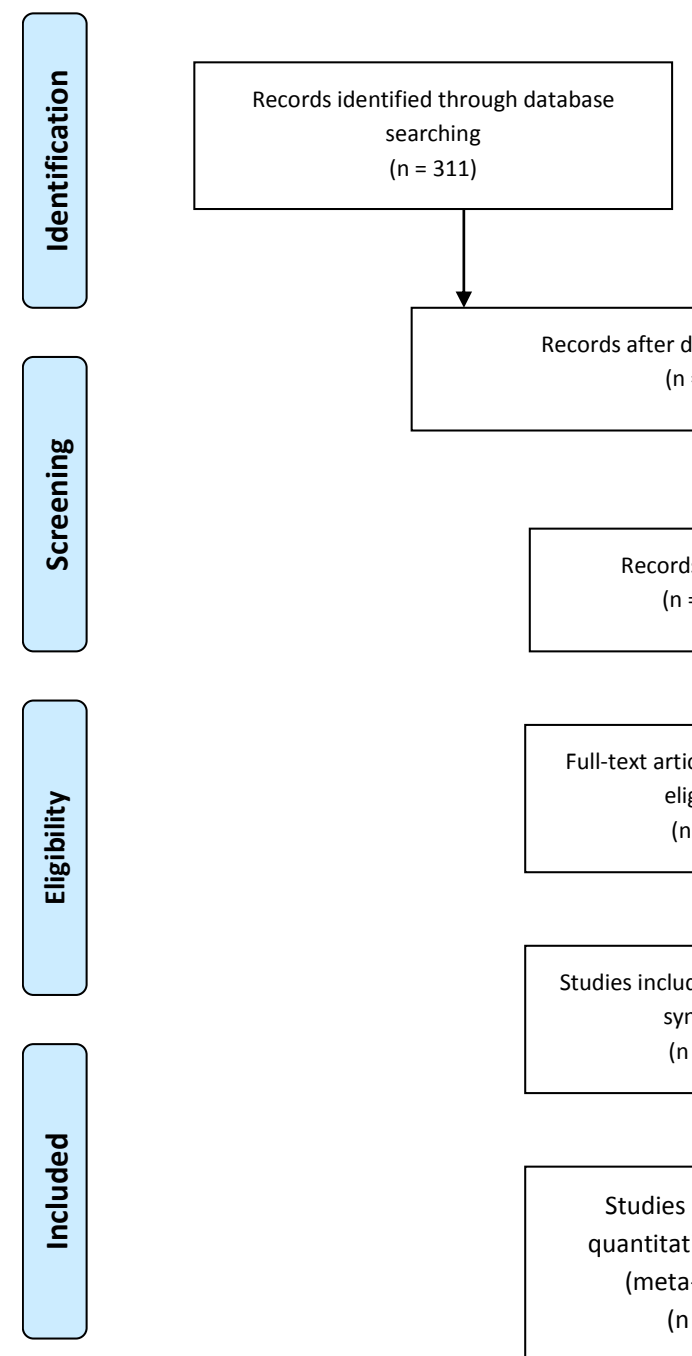

Additional records identified through other

sources

$(n=29)$

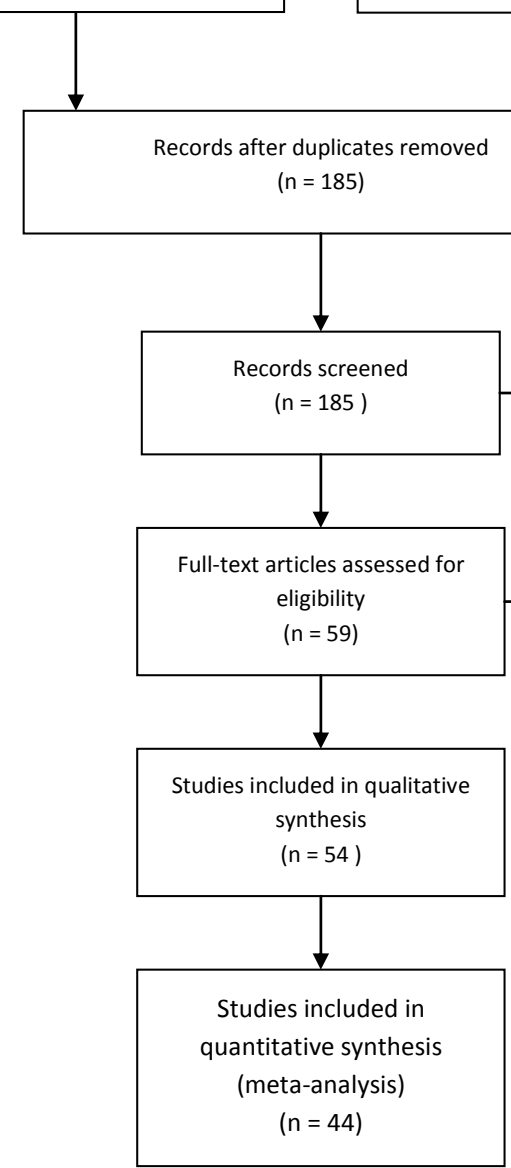

Fig. 1. Flow-chart of the present meta-analysis, carried out according to the Preferred Reporting Items for Systematic Reviews and Meta-analyses (PRISMA) guidelines.

\section{Sensitivity analysis}

A sensitivity analysis was performed and the results did not change pre- and post-analysis (Fig. 3).

\section{Cumulative meta-analysis}

Studies were cumulated by the year of publication and the results did not change pre- and post-cumulative meta-

Table 1. The main features of studies selected in the present systematic review and meta-analysis.

\begin{tabular}{|c|c|c|c|c|c|c|c|}
\hline First author & Year & Sample size & $\begin{array}{c}\text { Prevalence rate } \\
(\%)\end{array}$ & City & Male & Female & $\begin{array}{c}\text { Age of mother } \\
\text { (year) }\end{array}$ \\
\hline Khoori & 1999 & 2183 & $6.30 \%$ & Gorgan & 63 & 74 & NA \\
\hline Shadzi & 2000 & 848 & $5.90 \%$ & Esfahan & 21 & 28 & NA \\
\hline Amani & 2000 & 876 & $7.30 \%$ & Ahvaz & NA & NA & NA \\
\hline Eslami & 2002 & 5121 & $7.97 \%$ & Yazd & 186 & 271 & NA \\
\hline Mousafarkhani & 2002 & 803 & $12 \%$ & Ghoochan & 59 & 37 & NA \\
\hline Zahedpasha & 2004 & 2228 & $7.70 \%$ & Babol & 66 & 104 & NA \\
\hline Hoseini & 2005 & 2016 & $4.20 \%$ & Tonekabon & 41 & 44 & NA \\
\hline Oskouie & 2005 & 1000 & $14.70 \%$ & Tehran & NA & NA & $20-24$ \\
\hline Adlshoar & 2005 & 2500 & $5.20 \%$ & Rasht & NA & NA & NA \\
\hline Ramezanali & 2006 & 1419 & $9.09 \%$ & Tehran & NA & NA & $26.08 \pm 4.96$ \\
\hline Rafeie & 2007 & 4022 & $9.10 \%$ & Arak & 161 & 205 & NA \\
\hline Taheri & 2007 & 2558 & $7.90 \%$ & Birjand & 88 & 114 & $26.09 \pm 5.6$ \\
\hline Roudbari & 2007 & 1109 & $11.81 \%$ & Zahedan & 65 & 66 & NA \\
\hline
\end{tabular}




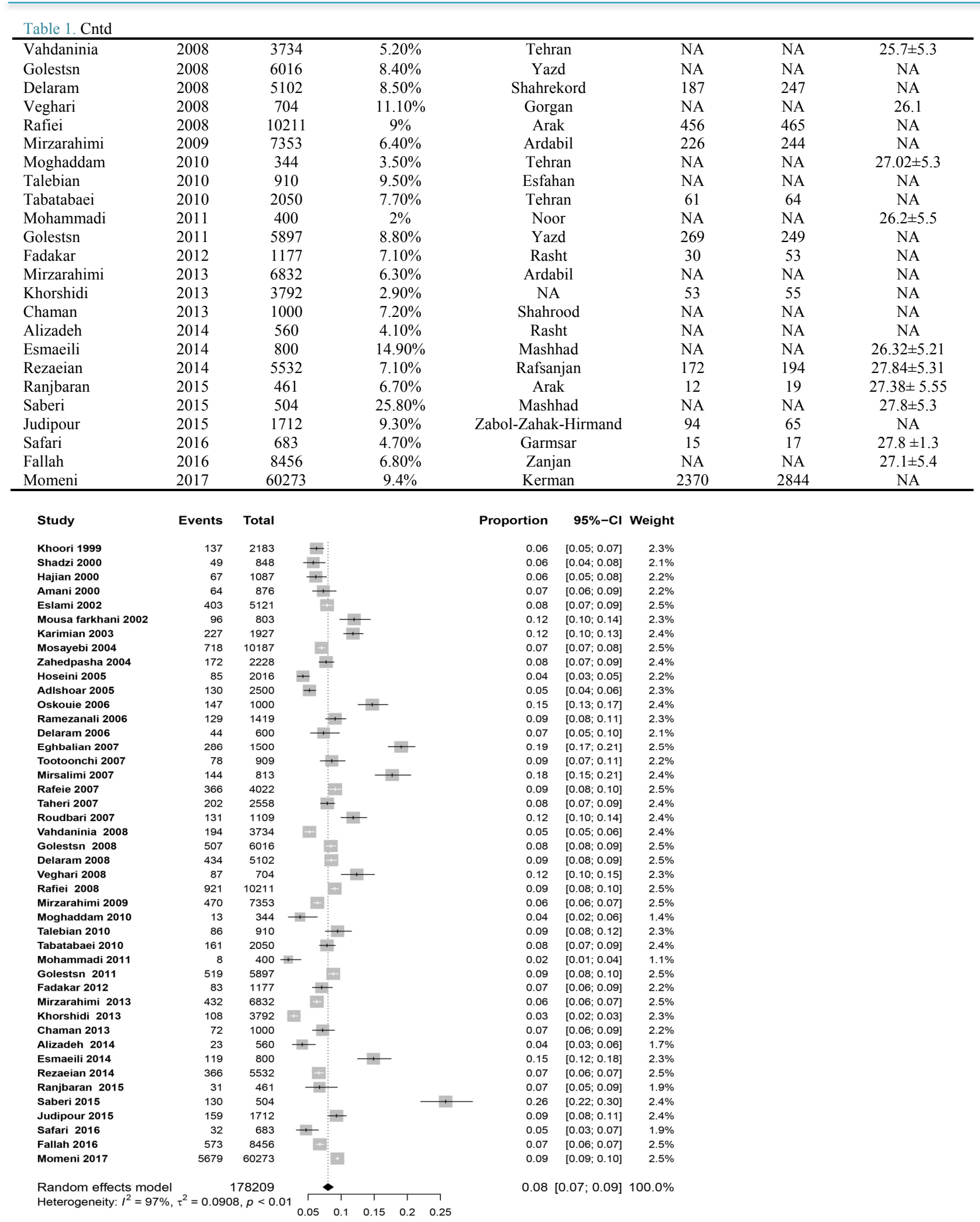

Fig. 2. The overall prevalence rate of low birth weight in Iran.

analysis (Fig. 4).

The main findings of the meta-regressions

Table 4 reports the findings of the meta-regression analyses, which are pictorially shown in Fig. 5 based on the sample size (Fig. 5A) and on the year of publication (Fig. 5B).

$4 \quad$ http://mjiri.iums.ac.ir

Med J Islam Repub Iran. 2018(13 Feb); 32:13.

\section{Publication bias}

The results of the Egger's test $(p=0.1927)$ are shown in Fig. 6. No publication bias could be observed. 
Table 2. Subgroup analyses carried out in the present meta-analysis.

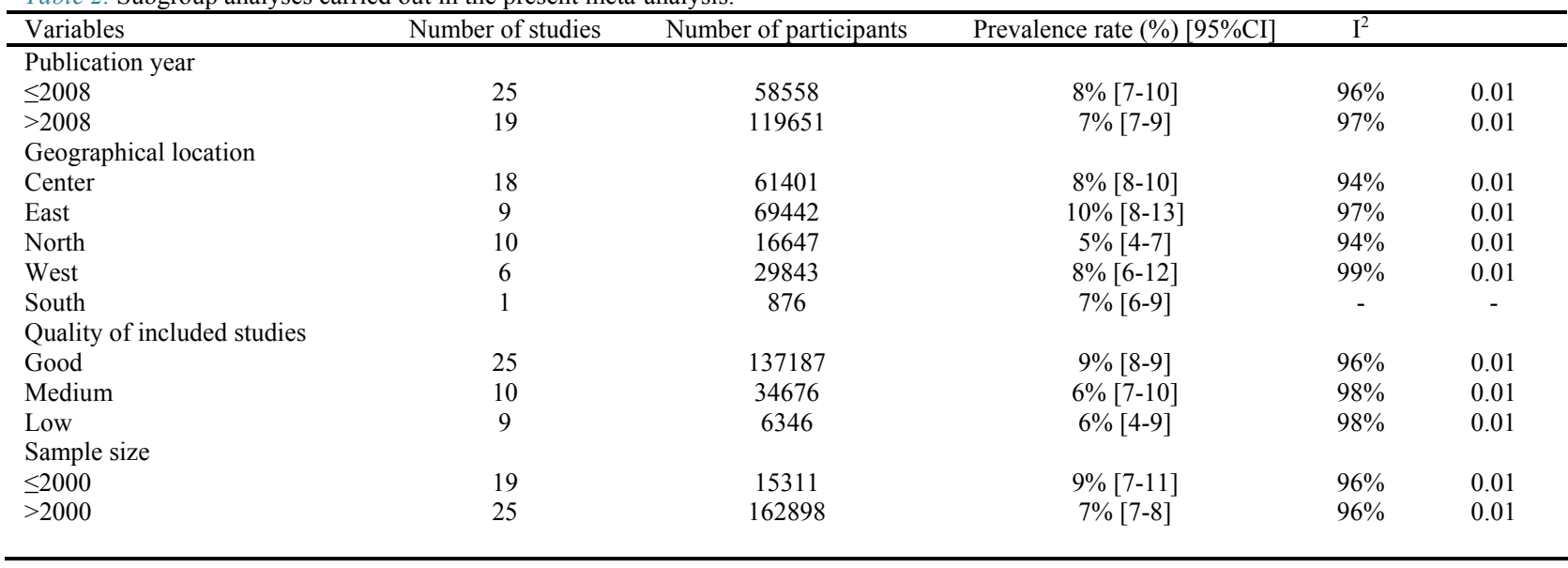

Table 3. Risk factors for low birth weight highlighted in the studies included in the present meta-analysis

Socio-demographic variables of the mother

Age, ethnicity, education level, socioeconomic level of the household, job, place of living (urban versus rural)

Gynecological/obstetric variables of the mother

Gravidity and parity, rank of pregnancy, type of delivery, a history of abortion, preeclampsia, previous LBW newborns, previous episodes of

bleeding or spotting, unwanted pregnancies, twining or multiple births

Clinical variables of the mother

Nutritional status, smoking status, insufficient care during pregnancy, underlying disease (including diabetes and metabolic syndrome, hypertension, cardiovascular disease, urinary tract infections, pulmonary disease, kidney disease, anemia), use of ferrous sulfate and other supplements during pregnancy, history of drug use

Socio-demographic variables of newborns

Gender

Other variables

Air pollution

Table 4. Meta-regressions based on the sample size and publication year.

\begin{tabular}{lcccccc}
\hline Variables & Estimate & Standard error & Z-val & p-value & Lower 95\%CI & Upper 95\%CI \\
\hline Year of publication & -0.0025 & 0.0109 & -0.2264 & 0.8209 & -0.0239 & 0.0190 \\
Sample size & 0.000 & 0.000 & 0.1231 & 0.9020 & -0.000 & 0.000 \\
\hline
\end{tabular}

\section{Discussion}

LBW significantly affects the physical and mental development of children, as well as their survival. LBW can, indeed, cause serious infant morbidity and mortality.

We aimed to investigate LBW prevalence rate in Iran, which was computed to be $8 \%(95 \%$ CI $7-9)$. This figure is well comparable with the prevalence rates of LBW in other countries, reported in Table $5(2,63-72)$. This could be due to the advancements and progresses achieved by the Iranian National Health System.

In the investigations selected in the present systematic review and meta-analysis, several risk factors have been highlighted, the most important of which were maternal age, education level, occupation, smoking status, gravidity and parity, birth rank, and type of delivery. The risk factors observed in these studies were consistent with those reported in the studies carried out worldwide $(64,68,70$, 72).

As previously mentioned, maternal age is among the most critical risk factors for LBW. Several studies showed that infants born from younger women (10-19 years) compared to older women were more likely to suffer from LBW (73-75).

Another critical risk factor is given by a low maternal education level (76-78). Mahmoodi et al. found that LBW in pregnant women with low literacy levels was three times higher than in women with higher education (79).

Other studies have underlined the role of birth rank, showing a higher risk of LBW during the first pregnancy, when compared to subsequent pregnancies. Factors such as economic status, education level and weight during pregnancy could play a role (80). Also, the type of delivery could influence the prevalence rate of LBW, with studies revealing higher LBW rates in women undergoing cesarean delivery. However, this finding is controversial, in that in other studies, the risk for LBW was reported to be higher among women undergoing cesarean delivery (67).

Employment of pregnant women in hard, tiring and stressful jobs is among the factors affecting LBW, preterm delivery and fetal death (81). Workplace condition is also an important predictor of pregnancy- and delivery-related outcomes. Various studies indicated that the type of job, as well as working conditions, might lead to LBW (82$85)$.

In addition, smoking has dangerous side effects for pregnant women. Any type of smoking during pregnancy could lead to LBW, respiratory problems, mental and learning impairment, birth defects, premature births and even infant death (86-89). 


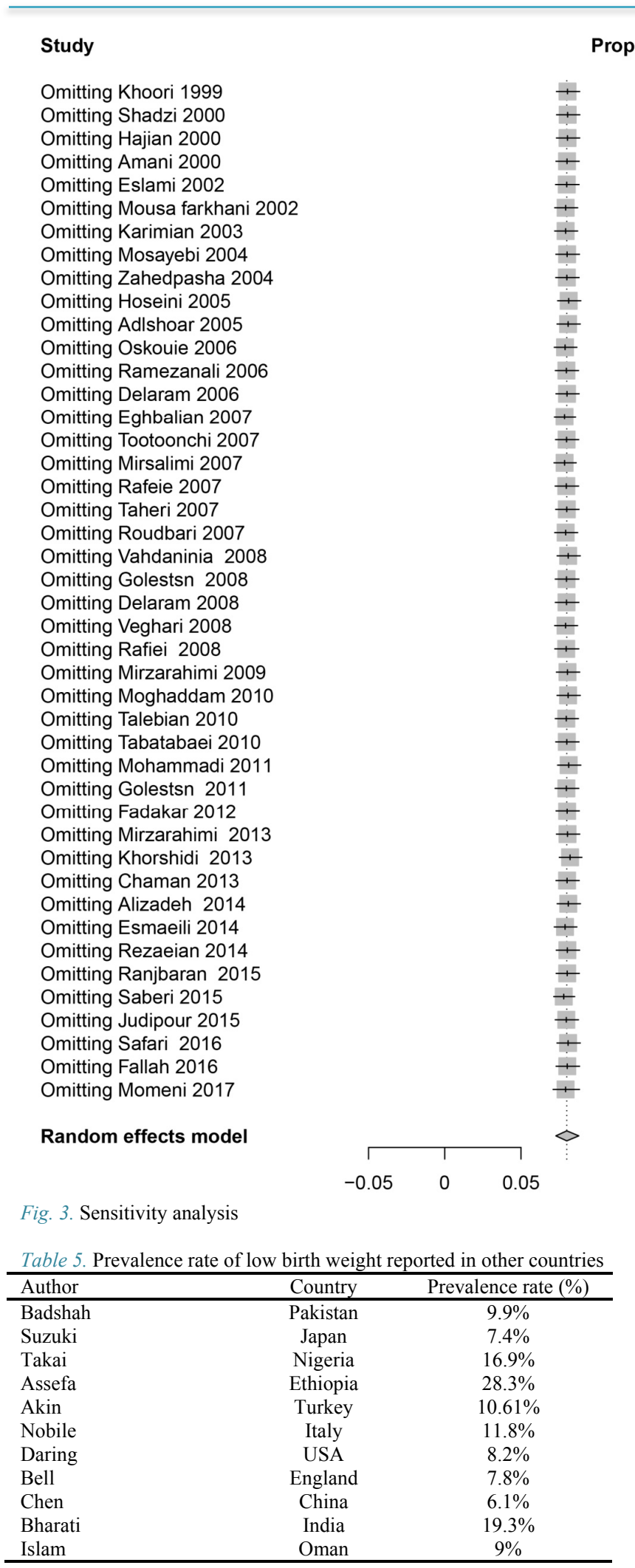

Comparative studies on LBW carried out in different provinces of Iran revealed that different climatic conditions, cultural variation, and socioeconomic conditions can have a great impact on increased LBW rate. Iran is, indeed, a vast country and living conditions may vary in different regions of the nation $(72,90)$. LBW prevalence

\section{$\quad 95 \%-\mathrm{Cl}$}

$0.08[0.07 ; 0.09]$

$0.08[0.07 ; 0.09]$

$0.08[0.07 ; 0.09]$

$0.08[0.07 ; 0.09]$

$0.08[0.07 ; 0.09]$

$0.08[0.07 ; 0.09]$

$0.08[0.07 ; 0.09]$

$0.08[0.07 ; 0.09]$

$0.08[0.07 ; 0.09]$

$0.08[0.07 ; 0.09]$

$0.08[0.07 ; 0.09]$

$0.08[0.07 ; 0.09]$

$0.08[0.07 ; 0.09]$

$0.08[0.07 ; 0.09]$

0.08 [0.07;0.09]

$0.08[0.07 ; 0.09]$

$0.08[0.07 ; 0.09]$

$0.08[0.07 ; 0.09]$

$0.08[0.07 ; 0.09]$

$0.08 \quad[0.07 ; 0.09]$

$0.08[0.07 ; 0.09]$

$0.08[0.07 ; 0.09]$

0.08 [0.07;0.09]

$0.08[0.07 ; 0.09]$

$0.08[0.07 ; 0.09]$

$0.08[0.07 ; 0.09]$

$0.08[0.07 ; 0.09]$

$0.08 \quad[0.07 ; 0.09]$

$0.08[0.07 ; 0.09]$

$0.08[0.07 ; 0.09]$

0.08 [0.07;0.09]

$0.08[0.07 ; 0.09]$

$0.08[0.07 ; 0.09]$

$0.08[0.08 ; 0.09]$

$0.08[0.07 ; 0.09]$

0.08 [0.07;0.09]

$0.08[0.07 ; 0.09]$

$0.08[0.07 ; 0.09]$

0.08 [0.07;0.09]

$0.08[0.07 ; 0.09]$

0.08 [0.07;0.09]

$0.08[0.07 ; 0.09]$

$0.08[0.07 ; 0.09]$

$0.08[0.07 ; 0.09]$

$0.08[0.07 ; 0.09]$ rate was higher in large provinces of Iran including Tehran, Razavi Khorasan, South Khorasan, SistanBaluchestan, and Qom. With high population density in these areas, pregnant women may face difficulties in receiving adequate prenatal care. Such prevalence may be increased due to urban-related issues, such as air pollution 


\section{Study}

Adding Khoori 1999 ( $k=1)$

Adding Shadzi $2000(\mathrm{k}=2)$

Adding Hajian $2000(\mathrm{k}=3)$

Adding Amani $2000(k=4)$

Adding Eslami $2002(k=5)$

Adding Mousa farkhani $2002(\mathrm{k}=6)$

Adding Karimian $2003(k=7)$

Adding Mosayebi 2004 ( $k=8$ )

Adding Zahedpasha $2004(\mathrm{k}=9)$

Adding Hoseini $2005(\mathrm{k}=10)$

Adding Adlshoar $2005(\mathrm{k}=11)$

Adding Oskouie 2006 ( $k=12)$

Adding Ramezanali 2006 ( $\mathrm{k}=13$ )

Adding Delaram 2006 ( $k=14)$

Adding Eghbalian 2007 ( $\mathrm{k}=15)$

Adding Tootoonchi $2007(\mathrm{k}=16)$

Adding Mirsalimi $2007(\mathrm{k}=17)$

Adding Rafeie 2007 ( $k=18)$

Adding Taheri 2007 ( $k=19)$

Adding Roudbari 2007 ( $k=20)$

Adding Vahdaninia $2008(\mathrm{k}=21)$

Adding Golestsn $2008(\mathrm{k}=22)$

Adding Delaram $2008(\mathrm{k}=23)$

Adding Veghari $2008(\mathrm{k}=24)$

Adding Rafiei 2008 ( $k=25)$

Adding Mirzarahimi $2009(\mathrm{k}=26)$

Adding Moghaddam $2010(k=27)$

Adding Talebian $2010(\mathrm{k}=28)$

Adding Tabatabaei $2010(\mathrm{k}=29)$

Adding Mohammadi $2011(\mathrm{k}=30)$

Adding Golestsn 2011 ( $\mathrm{k}=31)$

Adding Fadakar $2012(\mathrm{k}=32)$

Adding Mirzarahimi $2013(\mathrm{k}=33)$

Adding Khorshidi $2013(\mathrm{k}=34)$

Adding Chaman $2013(\mathrm{k}=35)$

Adding Alizadeh $2014(\mathrm{k}=36)$

Adding Esmaeili $2014(\mathrm{k}=37$ )

Adding Rezaeian 2014 ( $\mathrm{k}=38$ )

Adding Ranjbaran $2015(\mathrm{k}=39)$

Adding Saberi $2015 \quad(k=40)$

Adding Judipour $2015(\mathrm{k}=41)$

Adding Safari $2016(\mathrm{k}=42)$

Adding Fallah $2016(\mathrm{k}=43)$

Adding Momeni 2017 ( $k=44$ )

Random effects model

Fig. 4. Cumulative meta-analysis

A

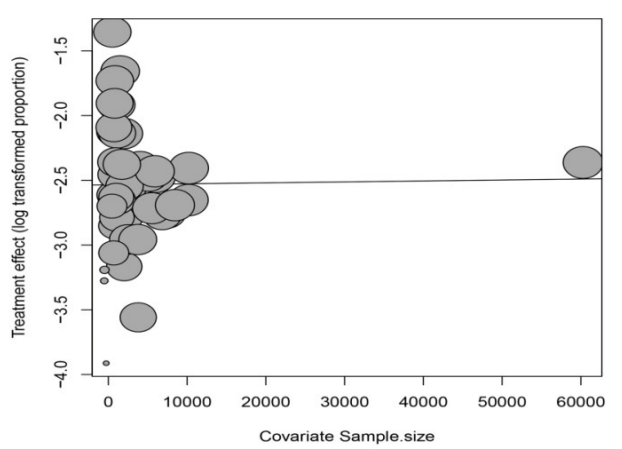

\section{Proportion $\quad 95 \%-\mathrm{C}$}

$0.06[0.05 ; 0.07]$

$0.06[0.05 ; 0.07]$

0.06 [0.05; 0.07]

0.06 [0.06;0.07]

$0.07[0.06 ; 0.08]$

$0.07 \quad[0.06 ; 0.09]$

$0.08[0.06 ; 0.10]$

$0.08[0.07 ; 0.09]$

$0.08 \quad[0.07 ; 0.09]$

0.07 [0.06; 0.09]

$0.07[0.06 ; 0.08]$

$0.08 \quad[0.06 ; 0.09$ ]

0.08 [0.06; 0.09$]$

0.08 [0.06;0.09]

$0.08 \quad[0.07 ; 0.10]$

$0.08[0.07 ; 0.10]$

$0.09[0.07 ; 0.10]$

$0.09[0.07 ; 0.10]$

$0.09[0.07 ; 0.10]$

$0.09[0.07 ; 0.10]$

$0.08[0.07 ; 0.10]$

$0.08 \quad[0.07 ; 0.10]$

0.08 [0.07;0.10]

$0.09[0.07 ; 0.10]$

$0.09[0.08 ; 0.10]$

$0.09[0.08 ; 0.10]$

$0.08 \quad[0.07 ; 0.09]$

$0.08 \quad[0.07 ; 0.09$ ]

$0.08 \quad[0.07 ; 0.09]$

0.08 [0.07;0.09]

$0.08 \quad[0.07 ; 0.09]$

$0.08 \quad[0.07 ; 0.09]$

$0.08[0.07 ; 0.09]$

0.08 [0.07; 0.09]

$0.08 \quad[0.07 ; 0.09]$

$0.08[0.07 ; 0.09]$

0.08 [0.07; 0.09 ]

$0.08 \quad[0.07 ; 0.09]$

0.08 [0.07;0.09]

$0.08 \quad[0.07 ; 0.09]$

$0.08 \quad[0.07 ; 0.09]$

$0.08 \quad[0.07 ; 0.09]$

$0.08 \quad[0.07 ; 0.09]$

0.08 [0.07;0.09]

$0.08[0.07 ; 0.09]$

Fig. 5. Association between LBW by sample size (A) and year of publication (B)

and stress, among others. The impact of air pollutants such as $\mathrm{SO}_{2}, \mathrm{NO}_{2}, \mathrm{PM} 2.5$, and PM10 on pregnant women is remarkable $(87,91,92)$.
Concerning the gender of newborns, the results of our investigation failed to reveal any gender-based differences in LBW prevalence rate. The findings are in line with in- 


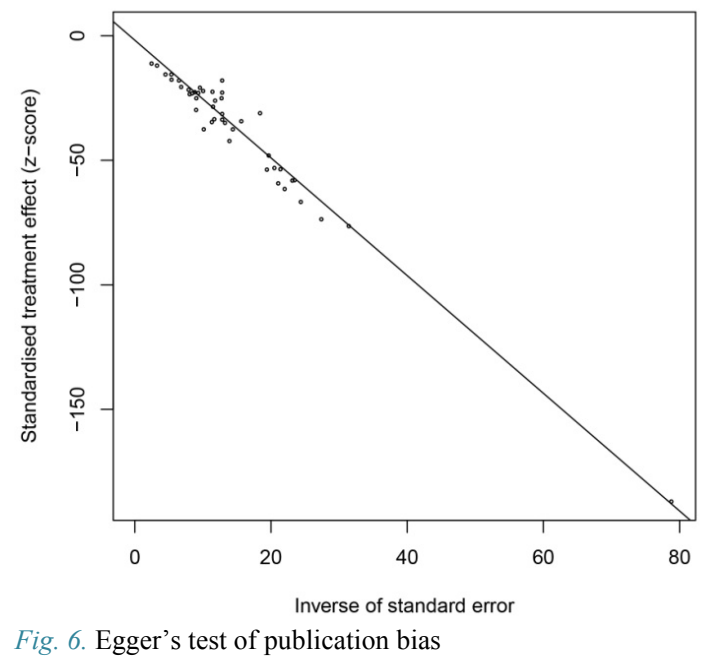

vestigations performed in countries such as Turkey and China $(66,93)$.

We could not detect any significant association between LBW rate in Iran and sample size as well as between LBW prevalence and year of publication.

Our meta-analysis is not free from limitations, and several shortcomings should be recognized. First, there is a dearth of studies focusing on LBW rate for some provinces of Iran. In addition, the heterogeneity rate (97\%) was high and statistically significant. Another limitation was that $11.4 \%$ of studies were of low quality.

\section{Conclusion}

The prevalence of LBW was estimated to be $8 \%$ in Iran, a rate comparable with other countries, both developed and developing. This could be due to the health reforms implemented in Iran throughout the years. Also, risk factors for LBW are in line with the extant literature. However, due to the limitations of the current meta-analysis further research is warranted.

\section{Funding/Support}

Iran University of Medical Sciences, Tehran, Iran (Grant No: 30047-193-04-95)

\section{Conflict of Interests}

The authors declare that they have no competing interests.

\section{References}

1. Borja JB, Adair LS. Assessing the net effect of young maternal age on birthweight. Am J Hum Biol. 2003;15:733-40.

2. Badshah S, Mason L, Mckelvie K, Payne R, Lisboa PJ. Risk factors for low birthweight in the public-hospitals at Peshawar, NWFPPakistan BMC Public Health. 2008;8:197.

3. Sicuri E, Bardají A, Sigauque B, Maixenchs $M$, Nhacolo A, Nhalungo D, et al. Costs associated with low birth weight in a rural area of Southern Mozambique. PLoS One. 2011;6:e28744.

4. DiRienzo AG. Parsimonious conditional-mean model selection with multiple covariates: an analysis of infant mortality in the USA. Stat Med. 2013;32:4259-74.

5. Forsen T, Eriksson J, Tuomilehto J, Reunanen A, Osmond C, Barker D. The fetal and childhood growth of persons who develop type 2 diabetes. Ann Intern Med. 2000;133:176-82.

6. Astone NM, Misra D, Lynch C. The effect of maternal socio- economic status throughout the lifespan on infant birthweight Paediatr Perinat Epidemiol. 2007;21:310-8

7. Emanuel I, Kimpo C, Moceri V. The association of maternal growth and socio-economic measures with infant birthweight in four ethnic groups. Int J Epidemiol 2004; 33: 1236-42.

8. Valero De Bernabe J, Soriano T, Albaladejo R, Juarranz M, Calle ME, Martinez D, et al. Risk factors for low birth weight: a review. Eur J Obstet Gynecol Reprod Biol 2004; 116: 3-15.

9. de Wilde JA, van Buuren S, Middelkoop BJ. Trends in birth weight and the prevalence of low birth weight and small-for-gestational-age in Surinamese South Asian babies since 1974: cross-sectional study of three birth cohorts. BMC Public Health. 2013;13:931.

10. Shin YH, Choi SJ, Kim KW, Yu J, Ahn KM, Kim HY, et al. Association between maternal characteristics and neonatal birth weight in a Korean population living in the Seoul metropolitan area, Korea: a birth cohort study (COCOA). J Korean Med Sci. 2013;28: 580-5.

11. Liberati A, Altman DG, Tetzlaff J, Mulrow C, Gøtzsche PC, Ioannidis JP, et al. The PRISMA statement for reporting systematic reviews and meta-analyses of studies that evaluate health care interventions: explanation and elaboration. Ann Intern Med. 2009; 151:W65-94

12. von Elm E, Altman DG, Egger M, Pocock SJ, Gøtzsche PC, Vandenbroucke JP; STROBE Initiative. The Strengthening the Reporting of Observational Studies in Epidemiology (STROBE) statement: guidelines for reporting observational studies. Lancet. 2007;370:1453-7.

13. DerSimonian R, Laird N. Meta-analysis in clinical trials. Control Clin Trials. 1986;7:177-88.

14. (14) Baker WL, White CM, Cappelleri JC, Kluger J, Coleman CI; Health Outcomes P, and Economics (HOPE) Collaborative Group,. Understanding heterogeneity in meta-analysis: the role of metaregression. Int J Clin Pract. 2009;63:1426-34.

15. Higgins J, Thompson SG. Quantifying heterogeneity in a metaanalysis. Stat Med. 2002;21:1539-58.

16. Copas J, Shi JQ. Meta-analysis, funnel plots and sensitivity analysis. Biostatistics. 2000;1:247-62.

17. Phan K, Tian DH, Cao C, Black D, Yan TD. Systematic review and meta-analysis: techniques and a guide for the academic surgeon. Ann Cardiothorac Surg. 2015;4:112-22.

18. Egger M, Davey Smith G, Schneider M, Minder C. Bias in metaanalysis detected by a simple, graphical test. BMJ.1997;315:629-34.

19. Khoori E, Vakili MA, Golalipour MJ. Low birth weight and some factors affect it in newborns (Gorgan 1996). J Gorgan Uni Med Sci. 1999; $1: 46-53$.

20. (Amani R. Assessment of the rate of low birthweight and its related factors in Ahvaz, Iran, in 1995 and 1996. Food Nutr Bull 2000; 21: 290-2.

21. Hajian K. A study of the Prevalence of low Birth weight and its Risk Factors in Babol, in 1998. J Mazandaran Univ Med Sci. 2000;10: 49-56.

22. Shadzi Sh, Mohammadzadeh Z, Mostafavi F, Hassanzadeh A. The prevalence of low birth weight and maternal risk factors in Isfahan. J Guilan Univ Med Sci. 2000;9:55-61.

23. Eslami Z, Aflatounian A. A study to determine the prevalence of low birth weight (LBW) infants in Yazd. J Shaheed Sadoughi Univ Med Sci 2002; 1:3-8.

24. Mousa farkhani E. Prevalence of low birth weight infants and determine risk factors in Quchan in 2001. Razebehzistan. 2002;21: 2-6.

25. Karimian S, Molamohammadi M, Jandaghi Gh. The prevalence of low birthweight and risk factors in hospitals of Qom province in 2000-2001. Feyz. 2003;7:76-80.

26. Mosayebi Z, Fakhraee H, Movahedian AH. Prevalence and risk factors of low birth weight infants in Mahdieh hospital, Tehran. Feyz. 2004;8:58-67.

27. Zahed Pasha Y, Esmaeili Dooki M, Haji Ahmadi M, Asgardon G, Ghadimi R, Baleghi M, et al. Effect of Risk Factors on Low Birth Weight Neonates. JBUMS. 2004;6:18-24.

28. Adlshoar M, Pakseresht S, Baghaei M, Kazamnejad A. Survey predictive factors of neonatal low birth weight in mothers referring to hospitals in Rasht. Holist Nurs Pract. 2005;15:33-8.

29. Hosseini S.Z, Bahadori M.H, Fallah Bagher Shaidaei H. Incidence of low birth weight and associated risk factors during March 20022003 in Tonekabon, Iran. J Mazandaran Univ Med Sci. 2005;15: 
110-3.

30. Delaram M, Akbari N. Weight gain in pregnancy and its correlation with birth weight of infants in women Who reffered to obstetric wards of Hajar hospital in Shahrekord. Holist Nurs Pract. 2006;16: 8-13.

31. Oskouie F, Bagherzadeh A, Feizi Z, Mohmoodi M, Peyrovi H. The effect of air pollution on low birth weight: a cohort study. Int J Epidemiol. 2006;3:1-14.

32. Ramazanali F, Vahid Dastjerdi M, Beigi A, Moini A. The relationship between Maternal HCT levels, birth weight and risk of low birth weight. Iran J Pediatr. 2006;16:447-54.

33. Eghbalian F. Low birth weight causes survey in neonates. Iran J Pediatr. 2007;17:27-33.

34. Mirsalimi f, Sadeghi S. Some Maternal Factors Influencing Low Birth Weight in Women Attending Teaching Centers Affiliated with Iran University of Medical Sciences in 2004-2005. Nurs Midwifery J Tabriz Uni of Med Sci \& Health Serv. 2007;4:22-9.

35. Rafiei M. Prevalence of Low Birth Weight and Obesity and some concomitant factors in live offspring's in 2006 and compare with 2002 result's in Arak Talleghani Hospital. Iran J Pediatr. 2007;17: 47-53.

36. Roudbari M, Yaghmaei M, Soheili M. Prevalence and risk factors of low-birth-weight infants in Zahedan, Islamic Republic of Iran. East Mediterr Health J. 2007;13:838-45.

37. Taheri F, Kazemi T. Risk Factors for Low Birth Weight in Birjand, Iran (a case-control study). J Birjand Univ Med Sci. 2007;14:9-15.

38. Toutounchi P. Low birth weight among newborns infants tehran hospital. Iran J Pediatr. 2007;17:186-92.

39. Delaram M, Ahmadi A. Prevalence of Low Birth Weight and its Related Factors in Shahr-e-Kord. J Reprod Fertil 2008; 9: 263-70.

40. Golestan M, Fallah R, Akhavan Karbasi S. Neonatal mortality of low birth weight infants in Yazd, Iran. Int j reprod biomed. 2008;6: 205-8.

41. Rafiei M, Ayatollahi S. Prevalence of low birth weight and obesity in Central Iran. Early Child Dev Care. 2008;178:655-8.

42. Vahdaninia M, Tavafian SS, Montazeri A. Correlates of low birth weight in term pregnancies: a retrospective study from Iran. BMC Pregnancy Childbirth. 2008;8:12.

43. Veghari G, Nasiri H. Low birth weight and some related factors in the rural city of Gorgan. JGBFNM. 2008;16:18-25.

44. Mirzarahimi M, Sa'adati H, Berak M, Abbasgholizadeh N, Azami A, Enteshari A. Incidence and Risk Factors of Low-Birth-Weight Infants in hospitals of Ardebil J Ardabil Univ Med Sci. 2009;9:6979.

45. Moghadam banaem L, Seddighi Looye E, Kazemnejad A, Afshar A. Maternal and umbilical cord blood serum levels of zinc, copper, magnesium, iron and calcium and their relationship with low birth weight. Modares J Med Sci Pathol. 2010;13:43-50.

46. Tabatabai S, Moradi MH. Low birth weight risk factors survey in neonates in Tehran. Adv Nurs Midwifery. 2010;20:29-35.

47. Talebian MH, Afrouz G. The relationship between biological, psychological-cognitive and social-cultural characteristics of parents with infant' birth weight in Isfahan province. Health Serv Res. 2010; 6.

48. Golestan M, Akhavan Karbasi S, Fallah R. Prevalence and risk factors for low birth weight in Yazd, Iran. Singapore Med J. 2011; 52:730-3.

49. Mohammadi B, Moghaddam Banaem L, Asghari M. CRP Levels during First Trimester of Pregnancy is Associated with Preterm Labor and Low Birth Weight. Hayat. 2011;16:5-14.

50. Fadakar soogheh k, Ghavi A, Niknami M, Kazemnejad Leili E. Relationship between mothers'nutritional status and weight gain during pregnancy with loe birth weight. J Guilan Univ Med Sci. 2012;21:27-35.

51. Chaman R, Amiri M, Raei M, Ajami ME, Sadeghian A, Khosravi A. Low birth weight and its related risk factors in northeast iran. Iran J Pediatr. 2013;23:701-4.

52. Khorshidi M, Nooshirvanpour P, Najafi S. Incidence of low birth weight in Mazandaran Province, Northern Iran. Oman Med J. 2013; 28:39-41.

53. Mirzarahimi M, Hazrati S, Ahmadi P, Alijahan R. Prevalence and risk factors for low birth weight in Ardabil, Iran. IJN 2013; 4: 1823.

54. Alizadeh S, Namazi A, Pakseresht S. Prevalence and predictors of low birth weight in Guilan, Iran. Gynecol Obstet (Sunnyvale). 2014;
$4: 63$

55. Esmaeili H, Shahfarehat A, Mirzaei najm abadi Kh, Dadgar S, Karimi A, Khojaste gelaymi M. The Relationship between Maternal Body Mass Index at the Beginning of Pregnancy and Infants' Birth Weight and Pregnancy Outcomes. Iran J Obstet Gynecol Infertil. 2014;16:1-10.

56. Rezaeian M, Goujani R, Sheikh Fathollahi M, Vaziri Nejad R, Manshori A, Razi S. A Comparative Study on Prevalence of Preterm Birth and Low Birth Weight in Iranians and Afghans Races in Rafsanjan Nik-Nafs Hospital in 2011-2012. J Rafsanjan Univ Med Sci. 2014;13:67-82.

57. Judipour Z, Alimalayeri F, bagheri S, bazzi A, Judipour MA, Judipour M. A Survey on Anthropometric Parameters of Neonates at Birth and Some Effective Demographic Factors in Sistan Region. J Ilam Univ Med Sci. 2015;23:106-13.

58. Ranjbaran M, Jafary-Manesh H, Sajjadi-Hazaneh L, Eisaabadi S, Talkhabi S, Sadat Khoshniyat A, et al. Prevalence of Low Birth Weight and Some Associated Factors in Markazi Province, 20132014. World J Med Sci 2015; 12: 252-8.

59. Saberi M, Rahmani Sh. The relationship between anemia during pregnancy and birth weight. Iran J Obstet Gynecol Infertil. 2015;18: 6-10.

60. Fallah R, Kazemnejad A, Zayeri F, Shoghli A. Birthweight Related Factors in Northwestern Iran: Using Quantile Regression Method. Glob J Health Sci. 2016;8:116.

61. Safari M, Samiee A, Salehi F, Ahmadi SN, Ahmadi SS. The prevalence and related factors of low birth weight. Int J Epidemiol. 2016;3:214-21.

62. Momeni M, Danaei M, Kermani AJ, Bakhshandeh M, Foroodnia S, Mahmoudabadi Z, et al. Prevalence and Risk Factors of Low Birth Weight in the Southeast of Iran. Int J Prev Med. 2017;8.

63. Suzuki K, Tanaka T, Kondo N, Minai J, Sato M, Yamagata Z. Is maternal smoking during early pregnancy a risk factor for all low birth weight infants? . J Epidemiol. 2007;18:89-96.

64. Takai IU, Bukar M, Audu BM. A prospective study of maternal risk factors for low birth weight babies in Maiduguri, North-Eastern Nigeria. Niger J Basic Clin Sci. 2014;11:89-98.

65. Assefa N, Berhane Y, Worku A. Wealth Status, Mid Upper Arm Circumference (MUAC) and Antenatal Care (ANC) Are Determinants for Low Birth Weight in Kersa, Ethiopia. PLoS One. 2012; 7:e39957.

66. Akin Y, Cömert S, Turan C, Ünal O, Piçak A, Ger L, et al. Increasing Low Birth Weight Rates: Deliveries in a Tertiary Hospital in Istanbul. Iran J Pediatr. 2010;20:284-90.

67. Nobile CG, Raffaele G, Altomare C, Pavia M. Influence of maternal and social factors as predictors of low birth weight in Italy. BMC Public Health. 2007;7:192.

68. Darling RD, Atav AS. Risk factors for low birth weight in New York State Counties. Policy Polit Nurs Pract. 2012;13:17-26.

69. Bell R. Trends in birthweight in the north of England. Hum Fertil (Camb). 2008;111:1-8.

70. Chen Y, Li G, Ruan Y, Zou L, Wang X, Zhang W. An epidemiological survey on low birth weight infants in China and analysis of outcomes of full-term low birth weight infan. BMC Pregnancy and Childbirth. 2013;13:242.

71. Bharati P, Pal M, Bandyopadhyay M, Bhakta A, Chakraborty S, Bharati P. Prevalence and cause of low birth weight in India. Mal J Nutr. 2011;13:301-13.

72. Islam MM. Increasing Incidence of Infants with Low Birth Weight in Oman. Sultan Qaboos Univ Med J. 2015;15:e177-e83.

73. Coutinho PP, Cecatti JG, Surita FG, Souza JP, Morais SS. Factors associated with low birth weight in a historical series of deliveries in Campinas,Brazil. Rev Assoc Med Bras. 2009;55:692-9.

74. Thompson LA, Goodman DC, Chang CH, Stukel TA. Regional variation in rates of low birth weight. Pediatrics. 2005;116:1115-6.

75. Partington SN, Steber DL, Blair KA, Cisler RA. Second births to teenage mothers: Risk factors for low birth weight and preterm birth. Perspect Sex Reprod Health. 2009;41:101-9.

76. Auger N, Roncarolo F, Harper S. Increasing educational inequality in preterm birth in Que'bec, Canada, 1981_2006. J Epidemiol Community Health. 2010;65:1091-6.

77. Correia S, Barros H. Small-for-gestational age Portuguese babies: the effect of childhood social environment, growth and adult socioeconomic conditions. Prev Med. 2015;70:102-7.

78. Pillas D, Marmot M, Naicker K, Goldblatt P, Morrison J, Pikhart H. 
Social inequalities in early childhood health and development: a European-wide systematic review. Paediatr Res. 2014;76:418-24.

79. Mahmoodi Z, Karimlou M, Sajjadi H, Dejman M, Vameghi M, Dolatian M. Working Conditions, Socioeconomic Factors and Low Birth Weight: Path Analysis. Iran Red Crescent Med J. 2013;15: 836-42.

80. Ngwira A, Stanley CC. Determinants of Low Birth Weight in Malawi: Bayesian Geo-Additive Modelling. PLoS ONE. 2015;10: e0130057.

81. Meyer JD, Nichols GH, Warren N, Reisine S. Maternal occupation and risk for low birth weight delivery: assessment using state birth registry data. J Occup Environ Med. 2008;50:306-15.

82. Von Ehrenstein OS, Wilhelm M, Ritz B. Maternal Occupation and Term Low Birth Weight in a Predominantly Latina Population in Los Angeles, California. J Occup Environ Med. 2013;55:1046-51.

83. Bonzini M, Coggon D, Palmer KT. Risk of prematurity, low birthweight and pre-eclampsia in relation to working hours and physical activities: a systematic review. Occup Environ Med. 2007; 64: 228-43.

84. Li X, Sundquist J, Sundquist K. Parental occupation and risk of small-for-gestational-age births: a nationwide epidemiological study in Sweden. Hum Reprod. 2010;25:1044-50.

85. Pompeii LA, Savitz DA, Evenson KR, Rogers B, McMahon M. Physical exertion at work and the risk of preterm delivery and smallfor-gestational-age birth. Obstet Gynecol. 2005;106:1279-88.

86. McCormick MC, Brooks-Gunn J, Shorter T, Holmes JH, Wallace CY, Heagarty MC. Factors associated with smoking in low-income pregnant women: relationship to birth weight, stressful life events, social support, health behaviors and mental distress. J Clin Epidemiol. 1990;43:441-8.

87. Khader YS, Al-Akour N, Alzubi IM, Lataifeh I. The association between second hand smoke and low birth weight and preterm delivery. Matern Child Health J. 2011;15:453-9.

88. Chiolero A, Bovet P, Paccaud F. Association between maternal smoking and low birth weight in Switzerland: the EDEN study, Swiss Med Wkly. 2005;135:525-30.

89. Nigg JT, Breslau N. Prenatal smoking exposure, low birth weight, and disruptive behavior disorders. J Am Acad Child Adolesc Psychiatry. 2007;46:362-9.

90. Titaley CR, Dibley MJ, Agho K, Roberts CL, Hall J. Determinants of neonatal mortality in Indonesia. . BMC Public Health. 2008;8.

91. Maisonet M, Bush TJ, Correa A, Jaakkola JJ. Relation between ambient air pollution and low birth weight in the Northeastern United States. Environ Health Perspect. 2001;109:351-6.

92. Bell ML, Ebisu K, Belanger K. Ambient Air Pollution and Low Birth Weight in Connecticut and Massachusetts. Environ Health Perspect. 2007;115:1118-24.

93. Shin SM, Chang YP, Lee ES, Lee YA, Son DW, Kim MH, et al. Low birth weight,very low birth weight rates and gestational agespecific birth weight distribution of korean newborn infants. J Korean Med Sci. 2005;20:182-7. 